\title{
Necrotizing fasciitis: an alternative approach
}

\author{
R. PERCIVAL \\ F.R.C.S.
}

\author{
A. W. HARGREAVES \\ F.R.C.S.
}

Department of Surgery, Salford Royal Hospital, Salford M60 9EP

\section{Summary}

Three cases of necrotizing fasciitis are presented. The initial management of necrotizing fasciitis remains undisputed. However, following a limited success with a conventional treatment policy, a more radical approach with immediate skin grafting following debridement is suggested.

\section{Introduction}

In 1933, Meleney clearly distinguished 'streptococ$\mathrm{cal}^{2}$ gangrene from postoperative synergistic gangrene in a classical description. In modern surgical practice (Ledingham and Tehrani, 1975), necrotizing fasciitis is considered a more applicable term for 'streptococcal' gangrene in both descriptive and aetiological terms.

There are a number of reports indicating that postoperative synergistic gangrene is successfully treated with antibiotics (Grimshaw and Stent, 1945; Meleney, Friedman and Harvey, 1945; Meleney, Shambaugh and Millen, 1950; Hutchinson, Summerley and Lawson, 1976). In contrast, antibiotics and hyperbaric oxygen are ineffective with necrotizing fasciitis. Conventional treatment dictates that the only effective management is radical debridement of the area involved (Meleney, 1933; Wilson, 1952; Stone and Martin, 1972). Following debridement, skin grafts are applied as a second stage procedure only after the development of a clean, granulating recipient bed.

In this paper, three cases of necrotizing fasciitis are presented. Following a uniformly fatal outcome, an alternative approach is suggested.

\section{Case histories}

\section{Case 1}

An 83-year-old, white male was admitted on 7th November 1980, for an anal stretch and manual evacuation of faeces. He was a diabetic treated with oral hypoglycaemic agents. Under anaesthesia the rectum was found to be impacted with faeces and a posterior fissure-in-ano was noted. An anal stretch was performed to four fingers with a manual evacuation of faeces. Immediately following surgery he complained of persistent peri-anal pain. Twenty-four hours following surgery he went into acute retention and required urethral catheterization. He was treated with cotrimoxazole and mezlocillin. Four days following surgery he developed an extremely painful, bluish-black gangrenous area approximately $2 \mathrm{~cm}$ in diameter on the left buttock, $5 \mathrm{~cm}$ from the anal margin. He developed congestive cardiac failure and deterioration in his diabetic state. A diagnosis of necrotizing fasciitis was made and a radical debridement of the perineum was performed. A horseshoe area of perineal skin and sub-cutaneous fat was excised, leaving the anal canal intact. Following radical debridement his general condition improved dramatically. Following intensive nursing care with daily dressings of his wound, over the course of the next month it was clear that the gangrenous process had been effectively controlled. Indeed the wound began to show evidence of healing. However, 5 weeks following admission he collapsed, developed the signs of a massive cerebro-vascular accident and died.

\section{Case 2}

A 61-year-old obese female was admitted on 19th December 1980, with a small bowel obstruction secondary to a strangulated femoral hernia. Laparotomy was performed and the hernia was reduced and repaired, a strangulated loop of small bowel was resected and an end-to-end anastomosis performed. Immediately following surgery she developed a chest infection that was treated with physiotherapy, cephalosporin and metronidazole. Four days following surgery she developed a severe toxic confusional state. On abdominal examination there was a small amount of sero-purulent discharge from the wound with two small bluish necrotic areas, approximately 2 $\mathrm{cm}$ in diameter $5 \mathrm{~cm}$ lateral to the wound. A diagnosis of necrotizing fasciitis was made: a radical 


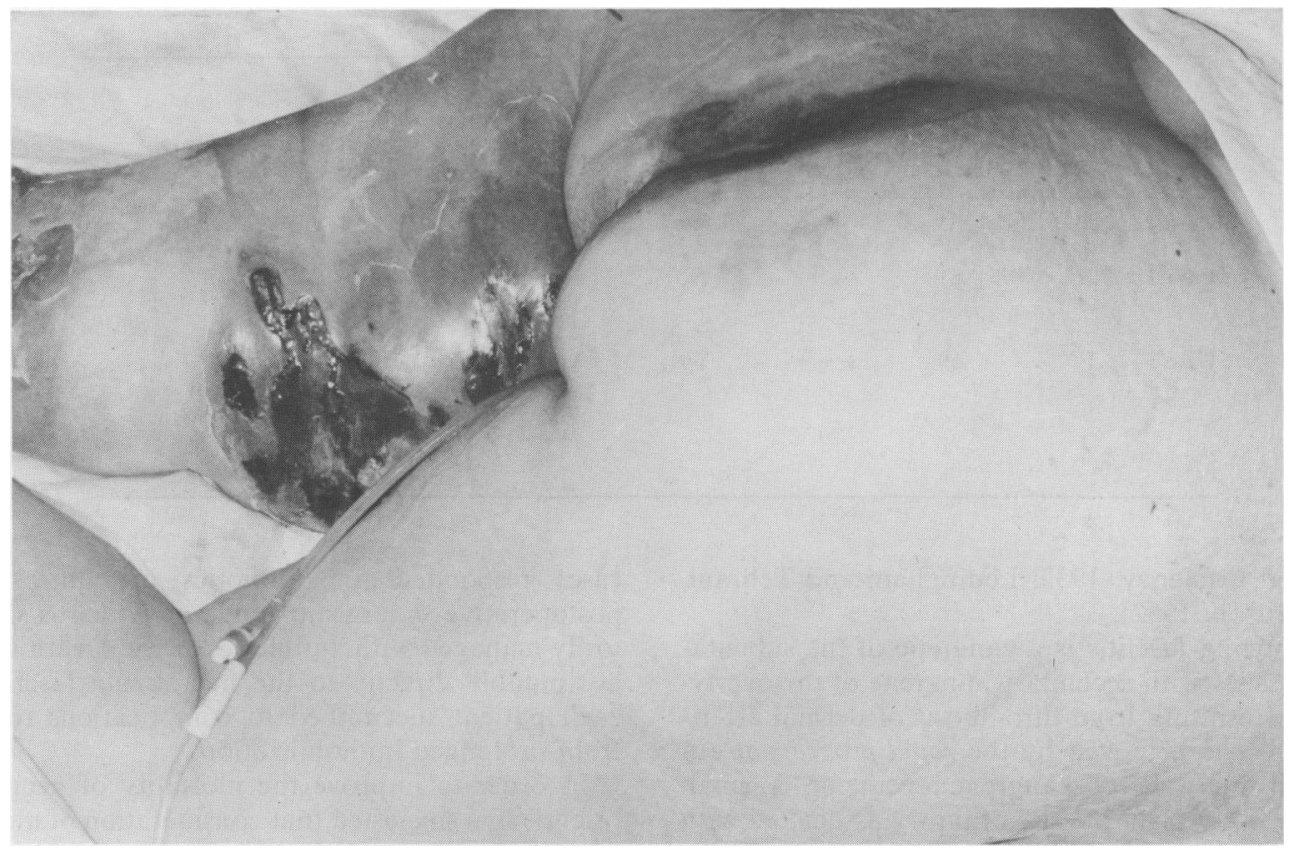

FIG. 1. The extent and appearance of necrotizing fasciitis in case 3.

debridement of the anterior abdominal wall was performed, necessitating removal of part of the laparotomy wound. Twenty-four hours following this she sustained a complete abdominal dehiscence which required repair. However, despite developing a small bowel fistula her general condition improved-no further gangrene developed. With intensive nursing care the abdominal defect was seen to be gradually healing over the next few months. A lengthy postoperative course was complicated by recurrent episodes of septicaemia, one of which proved fatal.

At post-mortem examination there was evidence of sub-acute bacterial endocarditis, with chronic pyelonephritis and a well walled-off chronic abscess cavity beneath her ileo-caecal anastomosis.

\section{Case 3}

A 59-year-old obese female was admitted on 5th January 1981, for control of her maturity onset diabetes mellitus. On examination there was an area of intertrigo in the left groin. Seven days following admission the area of intertrigo had progressed and had become frankly gangrenous (Fig. 1). A diagnosis of necrotizing fasciitis was made. She had been started on metronidazole, penicillin and flucloxacillin.
A radical debridement of the anterior abdominal wall and left thigh was performed. All the gangrenous skin and necrotic subcutaneous fat, including the deep fascia was excised. Immediately following surgery her general condition improved. It was clear over the next few days that the infective gangrenous process had been controlled. However, it was noted at that time that there was a sharp line of demarcation between diseased and normal tissues with no evidence of a zone of inflammation. Histology of the demarcation zone showed that beneath the intact epidermis, the dermis demonstrated patchy pericapillaritis. There was then a sharp change to necrotic nucleus-free epidermis with an increase in severity of the underlying peri-capillaritis, with thrombosis of capillaries. Under the intact epidermis, the junction of the dermis with sub-cutaneous fat had a dense band of polymorphs, largely in the fatty tissue suggestive of an inflammatory response.

Despite effective control of the infection there was never any evidence of healing. Four weeks following surgery she developed renal failure, and died six weeks after admission.

\section{Discussion}

The distinguishing features of necrotizing fasciitis and postoperative synergistic gangrene are well 
TABLE 1. Common features of the cases described

\begin{tabular}{|c|c|c|c|c|c|c|c|}
\hline & Sex & $\begin{array}{c}\text { Age } \\
\text { (years) }\end{array}$ & Obesity & $\begin{array}{l}\text { Diabetes } \\
\text { mellitus }\end{array}$ & $\begin{array}{l}\text { Onset of } \\
\text { gangrene } \\
\text { after } \\
\text { injury }\end{array}$ & $\begin{array}{l}\text { Antibiotics } \\
\text { before } \\
\text { development } \\
\text { of gangrene }\end{array}$ & $\begin{array}{c}\text { Organisms } \\
\text { isolated }\end{array}$ \\
\hline Case 1 & $\mathbf{M}$ & 83 & ++ & Yes & 4 days & Yes & $\begin{array}{l}\text { Escherichia coli } \\
\text { Acinetobacter }\end{array}$ \\
\hline Case 2 & $F$ & 61 & ++ & No & 4 days & Yes & $\begin{array}{l}\text { E. Coli } \\
\text { Proteus } \\
\text { Anaerobes }\end{array}$ \\
\hline Case 3 & $\mathbf{F}$ & 59 & +++ & Yes & 7 days & Yes & $\begin{array}{l}\text { E. Coli } \\
\text { Enterococcus } \\
\text { Non-haemolytic } \\
\text { streptococcus } \\
\text { Anaerobes }\end{array}$ \\
\hline
\end{tabular}

described (Meleney, 1933; Ledingham and Tehrani, 1975; Wilson, 1952).

Necrotizing fasciitis is a gangrene of the subcutaneous tissues with secondary gangrene of the overlying skin resulting from thrombosis of dermal arterioles. It is characterized by the rapid progression (in days) of an area of gangrene occurring a small distance away from the site of injury associated with a marked systemic upset. In contrast, postoperative synergistic gangrene involves the skin characterized by the slow progression (over weeks) spreading from the wound in all directions with minimal systemic upset. The aetiology of necrotizing fasciitis is thought to be bacterial synergism between aerobic and anaerobic organisms, the rapid spread of which is assisted by the relative avascularity of the tissue planes in conjunction with ischaemia and reduced host defence mechanisms.

These three cases demonstrate the classical features of necrotizing fasciitis (Table 1).

Two of our patients were diabetic but it is only recently that the ominous significance of diabetes mellitus has been emphasized. Rea and Wyrick (1970) noted a 63\% mortality in diabetics with necrotizing fasciitis-as compared with an overall mortality of $30 \%$ in their series of 44 patients. It is well known that in diabetes mellitus in addition to an impaired microvascular circulation, there is defective leucocyte function-specifically chemotactic activity-and hence damage to one of the major host mechanisms against infection (Mowatt and Baum, 1971; Miller and Baker, 1972). In Case 3 there was a discrepancy between the histology indicating a marked inflammatory response and the lack of inflammatory response seen macroscopically. The defective leucocyte function may explain this apparent discrepancy.

The infective gangrenous process was effectively controlled in these cases with the conventional treatment of radical debridement (Meleney, 1933; Wilson, 1952; Stone and Martin, 1972). None of the cases responded to antibiotics in contrast with postoperative synergistic gangrene which is satisfactorily managed with antibiotics alone. Death was not attributable directly to the necrotizing fasciitis but each patient succumbed to complications resulting from prolonged immobilization.

In order to improve the mortality of necrotizing fasciitis it is suggested that consideration of measures to reduce the period of immobilization and its associated morbidity is important. This can only be achieved by early skin cover. Burke, Bondoc and Quinby (1974) conducted a prospective trial to reevaluate primary excision with immediate skin grafting in burn patients. This technique was carefully evaluated in the mid-fifties and rejected, not because the concept was unsound, but because of the inability to solve the bacterial and physiological problems following primary excision at that time (MacMillan and Artz, 1957; Moncrieff, 1973). In modern practice these difficulties are more easily overcome. In Burke's series (Burke et al., 1974) the time required to close the defect with isograft skin was reduced substantially with a consequent improvement in mortality and morbidity in the immediate skin graft group.

Following our experience with necrotizing fasciitis - the management of which induces similar problems to those encountered in the treatment of burns-it is suggested that the concept of radical debridement with immediate skin grafting may be usefully applied in the treatment of this syndrome.

\section{References}

Burke, J.E., Bondoc, C.C. \& QuinBy, W.C. (1974) Primary burn excision and immediate grafting: a method of shortening illness. Journal of Trauma, 14, 389.

Grimshaw, C. \& STENT, L. (1945) Postoperative cutaneous gangrene: the effect of penicillin. Lancet, i, 434.

Hutchinson, P.E., Summerley, R. \& Lawson, L.J. (1976) Postoperative progressive gangrene: a reminder. British Journal of Dermatology, 94, 89.

Ledingham, I. MCA. \& Tehrani, M.A. (1975) Diagnosis, clinical 
course, and treatment of acute dermal gangrene. British Journal of Surgery, 62, 364.

MACMILLAN, B.G. \& ARTZ, C.P. (1957) A planned evaluation of early excision of more than $25 \%$ of the body surface in burns. Surgical Forum, 7, 88.

MELENEY, F.L. (1933) A differential diagnosis between certain types of infectious gangrene of skin. Surgery, Gynecology and Obstetrics, 56, 847.

Meleney, F.L., Friedman, S.T. \& Harvey, H.D. (1945) The treatment of progressive bacterial synergistic gangrene with penicillin. Surgery, 18, 423.

Meleney, F.L., Shambaugh, P. \& Millen, R.S. (1950) Systemic bacitracin in the treatment of progressive bacterial synergistic gangrene. Annals of Surgery, 131, 129.
MiLleR, M.F. \& BAKER, C. (1972) Leucocyte functions in juvenile diabetes mellitus: humoral and cellular aspects. Journal of Pediatrics, 81, 979.

MONCRIEFF, J.A. (1973) Burns: medical progress. New England Journal of Medicine, 288, 444.

MOWATT, A.G. \& BAUM, J. (1971) Chemostaxis of polymorphonuclear leucocytes from patients with diabetes mellitus. New England Journal of Medicine, 284, 621.

REA, W.J. \& WYRICK, W.J. (1970) Necrotising fasciitis. Annals of Surgery, 172, 957.

STONE, H.H. \& MARTIN, J.D. (1972) Synergistic necrotising cellulitis. Annals of Surgery, 175, 702.

WILSON, B. (1952) Necrotising fasciitis. American Surgeon, 18, 416. 